\title{
Mineração e Igreja: Uma questão socioambiental que desafia a evangelização
}

\author{
Mining and Church: \\ One environmental issue that challenges \\ evangelization
}

Afonso Murad

\section{Resumo}

A atividade mineradora causa profundo e prolongado impacto ambiental, além de interferir diretamente nas comunidades locais. Em 2013 constitui-se no Brasil uma articulação em torno da questão "Igreja e mineração". Após o encontro latino-americano de dezembro de 2014, organizou-se uma obra coletiva, publicada pela CNBB. Ela revela uma faceta pouco conhecida da relação conflituosa entre o cuidado com o meio ambiente, o ser humano (sobretudo os mais pobres) e a produção minerária. Será apresentada uma síntese dos temas abordados na obra "Igreja e mineração", na qual o autor atuou como um dos editores. A primeira parte descreve experiências de luta de grupos pastorais, em torno da ecologia, comunidade e mineração. A segunda parte, a análise crítica acerca da mineração. A seguir, uma leitura bíblico-teológica. E, na quarta parte, apresentam-se os critérios de discernimento em relação aos empreendimentos de mineração, emanados da Encíclica Laudato Si. Trata-se de um trabalho de "Teologia prática". Mostra-se assim como o espírito de diálogo e de serviço ao mundo, proclamado no Concílio Vaticano II, encontra eco e prolongamento em recentes iniciativas pastorais, sociais e ecológicas.

Palavras-chave: Igreja. Mineração. Ecoteologia. 


\begin{abstract}
The mining activity causes deep and prolonged environmental impact, in addition to interfere directly in local communities. In 2013 constitutes in Brazil a joint around the issue "Church and mining." After the Latin American meeting of December 2014, it organized a collective work, published by the CNBB. It reveals a little-known facet of the conflictual relationship between the care of the environment, the human being (especially the poor) and mining production. a summary of the topics covered in the book "Church and mining" will be presented, in which the author served as one of the editors. The first part describes pastoral groups fighting experiences around ecology, community and mining. The second part, the critical analysis of mining. Following is a biblicaltheological reading. And the fourth part presents the criteria of discernment regarding mining projects emanating from the Encyclical Laudato Si. It is a work of "practical theology". It is shown as well as the spirit of dialogue and service to the world, proclaimed the Second Vatican Council, echoed and extended in recent pastoral, social and ecological initiatives.
\end{abstract}

Keywords: Church. Mining. Ecotheology.

\title{
Introdução
}

O Vaticano II, na Constituição Pastoral Gaudium et Spes, inaugurou uma nova etapa na evangelização, ao sustentar que as alegrias e os sofrimentos, as conquistas e esperanças da humanidade são assumidas pelos seguidores de Cristo $^{1}$. Pois tudo o que é legitimamente humano, repercute na comunidade eclesial (GS 1). O Concílio perscruta os "Sinais dos Tempos" (GS 4). Reconhece que as grandes mudanças em curso oferecem oportunidades e desafios à fé cristã GS 5-8). Reflete sobre o sentido da atividade humana (GS 33-39). Mostra como há uma relação mútua entre Igreja e mundo (GS 40-43), de ensinar e aprender, contribuir e receber. Faz uma leitura teológica sobre vários temas contemporâneos à luz da fé cristã, como a cultura e a educação (GS

\footnotetext{
${ }^{1}$ Este artigo amplia e sistematiza a comunicação oral: Igreja e mineração: Uma questão socioambiental que desafia a fé cristã, apresentada no GT 08 - A Teologia em diálogo com a Ecologia: Deus, o ser humano e a natureza, do V Simpósio Internacional de Teologia - Concilium/PUC RIO, de 2015. O evento é intitulado: 50 anos do final do Concílio Vaticano II, 50 anos da Revista Concilium.
} 
53-62), a vida econômica e social (GS 63-72), a política e o espaço público (GS 73-76).

Mais de 50 anos depois, emergem novas questões. Ganha relevo o empenho para criar uma sociedade sustentável, que seja habitável para o ser humano e mantenha os ciclos vitais da biosfera. Eclode a consciência planetária ${ }^{2}$ : somos parte da Terra, o planeta se torna uno e assumimos a responsabilidade pela nossa Casa Comum. Em 2015, o Papa Francisco brinda ao mundo a Encíclica Laudato $\mathrm{Si}^{3}$, suscitando um amplo diálogo com políticos, pesquisadores, membros de movimentos socioambientais e cristãos de diferentes Igrejas. Estimula ações individuais, práticas comunitárias e políticas públicas em defesa da Casa Comum e dos pobres.

Neste contexto de uma "Igreja em saída"4, que atua na sociedade em vista da vida em plenitude, é que se coloca o tema da mineração. A atividade mineradora é pouco conhecida, sobretudo para os cidadãos urbanos. Como está longe dos nossos olhos, parece que não existe. Mas causa grande impacto ambiental, além de interferir diretamente nas comunidades locais. $\mathrm{O}$ crime ambiental na barragem de Fundão, na região de Mariana (MG) pôs a descoberto os riscos reais da atividade mineradora. Os impactos negativos para o ecossistema da bacia do Rio Doce, em curto e médio prazo, são incalculáveis ${ }^{5}$. Nos últimos anos, várias pastorais e organismos eclesiais tem se empenhado

\footnotetext{
${ }^{2}$ Cf. OLIVEIRA, P. A. R; SOUZA, J. A (Orgs). Consciência planetária e religião: desafios para o século XXI. São Paulo: Paulinas, 2009; MURAD, A. "Ecologia, consciência planetária e Bem Viver”. In: MURAD, A. (Org.). Ecoteologia. Um mosaico. São Paulo: Paulus, 2016, pp. 38-46.

${ }^{3}$ Papa FRANCISCO. Carta encíclica Laudato Si. Sobre o cuidado da casa comum. São Paulo: Paulinas, 2015.

${ }^{4}$ Expressão utilizada pelo Papa Francisco como título do capítulo I na Exortação Apostólica Evangelii Gaudium, sobre o anúncio do Evangelho no mundo atual. São Paulo, Paulinas, 2013, (EG 20,24,46).

${ }^{5}$ Há ampla bibliografia acerca das consequências do rompimento da barragem de rejeitos da mineração, da Samarco. Sugerimos aqui a revista Porantim, do CIMI (Conselho Indigenista Missionário, órgão da CNBB), novembro de 2015. Disponível em: <http://www.cimi.org. br/pub/Porantim/2015/Porantim380_nov2015.pdf $>$ ). E também a Revista do IHU, Instituto Humanitas, $\mathrm{n}^{\circ} 48$, de 2015. Disponível em: <http://ihu.unisinos.br/cadernos-ihu-em-formacao/ 550361-48o-edicao-mineracao-e-o-impulso-a-desigualdade-impactos-ambientais-e-sociais $>$. Para acompanhar os recentes conflitos das comunidades locais com as mineradoras no nosso continente, ver a página WEB do Observatorio de conflictos mineros de América Latina (OCMAL). Disponível em: <http://www.conflictosmineros.net/>. Informações atualizadas sobre os impactos ambientais na bacia do Rio Doce, no Estado do Espírito Santo, se encontram na comunidade do Facebook: $<$ https://www.facebook.com/F\%C3\%B3rum-Capixaba-emDefesa-da-Bacia-do-Rio-Doce-188140924863788/>. Acessos em 10 de junho de 2016.
} 
em causas sociais e ambientais. Dentre eles, surgiram iniciativas concretas que assumem a defesa da vida em toda a sua extensão, no confronto com a mineração.

A articulação latino-americana "Iglesias y Minería" (Igrejas e mineração), da qual participa o grupo brasileiro "Igreja e mineração", reúne várias instituições cristãs que atuam diretamente com as comunidades atingidas por atividades mineradoras. Dentre elas, destacam-se as equipes de JPIC (Justiça, Paz e Integridade da Criação) de institutos religiosos e grupos similares. Iglesias y Minería conta com o apoio de diversas dioceses católicas, da Red Eclesial Pan-Amazonica (REPAM), do departamento Justiça e Paz da Conferência Episcopal Latino-Americana (CELAM) e do Conselho Latino Americano das Igrejas Cristãs (CLAI). Na carta aberta "A Igreja não se deixa comprar" (2015), a representação de Iglesias y Minería afirma:

Conhecemos de perto o sofrimento de muitas comunidades e populações tradicionais, bem como as violações aos direitos ambientais e às futuras gerações provocadas pelos grandes empreendimentos mineiros em expansão em nosso continente. Diversos bispos e algumas conferências episcopais em muitas ocasiões têm se pronunciado em apoio às comunidades afetadas e denunciado os conflitos provocados pelas companhias mineradoras, muitas vezes com o aval dos Estados nacionais ${ }^{6}$.

Durante o encontro continental de "Igrejas e mineração", acontecido em dezembro de 2014, recolheram-se vários depoimentos. Eles constituíram o material básico para o vídeo homônimo, que foi enriquecido com tomadas nos locais ${ }^{7}$. Além disso, alguns agentes de pastoral que atuam neste âmbito escreveram artigos, nos quais apresentam suas experiências de compromisso com a questão socioambiental em locais de mineração. Outros colaboraram na reflexão bíblico-pastoral. Tais contribuições foram reunidas na obra "Igreja e mineração. Em defesa da Vida e dos Territórios" " ${ }^{8}$ Ela desvela a conflituosa relação entre o cuidado com o meio ambiente, as comunidades atingidas, a ex-

\footnotetext{
${ }^{6}$ Disponível em: <http://www.justicanostrilhos.org/A-igreja-nao-se-deixa-comprar>. Acesso em 10 de junho de 2016.

7 "Iglesias y minería, Igreja e mineração na América Latina (2015)". Disponível em: $<$ https://www.youtube.com/watch?v=Icr28HdyCfo $>$. Acesso em 10 de junho de 2016.

${ }^{8}$ MURAD, A; BOSSI, D. (Orgs.). Igreja e mineração. Em defesa da vida e dos territórios. Brasília: CNBB, 2015 (publicação da Comissão Episcopal para o serviço da Caridade, Justiça e Paz).
} 
tração e a produção minerária. Os temas abordados em "Igreja e mineração", na qual este autor atua como co-editor, exemplificam como é árdua a luta em defesa do meio ambiente e das comunidades atingidas. O livro recolhe diversas iniciativas, como:

- a experiência de Açalândia (Maranhão), descrita pelo Padre Dário Bossi, da articulação "Justiça sobre os trilhos";;

- a problemática da mineração em território indígena, apresentada por Egon Heck, do CIMI (Conselho Indigenista Missionário) ${ }^{10}$;

- a organização das comunidades na paróquia de Campo Alegre de Lourdes, na Diocese de Juazeiro (BA), em vista a ação devastadora da mineração na região, narrada por Ruben Siqueira, membro da Rede Brasileira de Justiça ambiental ${ }^{11}$,

- a peleja contra a mineração do urânio no interior do Ceará, narrada por Thiago Valentim, da CPT (Comissão Pastoral da Terra) ${ }^{12}$,

- a denúncia sobre a poluição do ar gerado pelo transporte de minério de ferro na ferrovia do aço, a partir do acampamento Irmã Dorothy, no sul fluminense, pelo educador Guilherme Gonzaga e a teóloga metodista Nancy Cardoso ${ }^{13}$.

Os autores reconhecem a importância econômica da mineração, mas questionam a forma como ela se realiza e sua inserção no mercado global. A partir do olhar das comunidades atingidas, das tentativas de diálogo com as mineradoras e o poder público, apontam sérias questões éticas, que desafiam a fé cristã. Não somente narram os fatos, mas também realizam uma análise crítica, que é completada com a uma visão sintética de Bruno Milanez ${ }^{14}$.

\footnotetext{
${ }^{9}$ BOSSI, D. "Uma luta desigual. Que vitória é possível? Experiências e reflexões no enfrentamento aos impactos da mineração". In: Igreja e mineração, pp. 15-27.

${ }^{10}$ HECK, H. "Igrejas e Mineração. Um olhar a partir dos Povos Indígenas". In: Igreja e mineração, pp. 29-46.

${ }^{11}$ SIQUEIRA, R. "Mineração: desafio para um povo que caminha na fé". In: Igreja e mineração, pp. 47-59.

${ }^{12}$ VALENTIM, T. “A peleja da vida contra o urânio”. In: Igreja e mineração, pp. 61-71.

${ }^{13}$ CARDOSO, N., GONZAGA, G. "O trem passa, a sujeira fica. Tampa o trem! Conversa com o assentamento Irmã Dorothy”. In: Igreja e mineração, pp. 73-84.

${ }^{14}$ MILANEZ, B. “O Brasil no contexto da mineração global”. In: Igreja e mineração, pp. $119-124$.
} 
No intuito de realizar uma leitura teológico-pastoral, utilizar-se-ão os textos de Sandro Galazzi ${ }^{15}$ Rodrigo Péret ${ }^{16}$, Marcelo Barros ${ }^{17}$ e Ari A. dos Reis ${ }^{18}$ que encerram a obra "Igreja e mineração". Também se recorrerá a alguns tópicos da Encíclica "Laudato Si', do Papa Francisco. Com isso, há material para uma análise consequente, mostrando a pertinência ética e espiritual do tema, a consistência e a atualidade das reflexões teológico-pastorais.

\section{As comunidades e a mineração}

Dário Bossi narra a luta das comunidades nas periferias de Açailândia, interior do Maranhão, no confronto com a atividade mineradora ${ }^{19}$. Ali se instalaram 14 fornos siderúrgicos, uma usina termelétrica, uma fábrica de cimento e uma aciaria, ainda em construção. Os missionários combonianos que atuam na região acompanham a luta pelos direitos socioambientais do povo. Os efeitos das repentinas mudanças se fizeram sentir. Além da poluição do ar, houve empobrecimento do solo com a implantação de grandes plantações de eucalipto para fornecer carvão para as siderúrgicas. Vários pequenos proprietários venderam suas terras e se dispersaram. Mas 21 famílias se organizaram e pediram indenização pelos danos à saúde e querem permanecer ali.

Este caso ilustra uma situação complexa, como outras similares no Brasil. Segundo Bossi ${ }^{20}$, milhares de outros maranhenses e paraenses sofreram em consequência dos projetos mineradores e siderúrgicos. Ao longo do Corredor de Carajás, implantado pela Vale, desde a maior mina de minério de ferro do mundo (Parauapebas-PA) até o porto marítimo mais fundo da América Latina (São Luís-MA), houve uma sequência de violentos ciclos econômicos e sociais, nos últimos 60 anos. No início, surge a exploração da madeira nobre. Arranca-se da floresta as árvores mais preciosas, destruindo com tratores o que estava em volta. Em breve, essa se exauriu e os madeireiros se associam a centenas de serrarias nas pequenas cidades da Amazônia Oriental. Essas

${ }^{15}$ GALAZZI, S. "Vida, Bíblia e Mineração”. In: Igreja e mineração, pp. 85-99.

${ }^{16}$ PÉRET, R. C. A. "A busca da mística de resistência e vida". In: Igreja e mineração, pp. 101-117.

${ }^{17}$ BARROS, M. “A aliança com a criação. Um olhar bíblico-teológico”. In: Igreja e mineração, pp. 125-127.

${ }^{18}$ REIS, A. A. "Igreja diante da mineração. Critérios pastorais". In: Igreja e mineração, pp. 127-131.

${ }^{19}$ BOSSI, D. "Uma luta desigual”, pp. 15-17.

${ }^{20}$ Cf. BOSSI, D. “Uma luta desigual”, pp. 18-19. 
atraem imigração de mão-de-obra barata para escoar madeira. Quando a floresta começa a se extinguir, os madeireiros migram mata adentro, atraindo atrás de si grandes fazendeiros do sul do País, com a pastagem e a criação de gado.

Para que o gado pudesse aproveitar do território, era necessário eliminar os resquícios de mata ("juquira") e usar os resíduos de madeira menos interessantes para as serrarias. Surge então o ciclo de mineração e siderurgia. Abre-se no final dos anos oitenta a grande ferrovia para o escoamento do minério de ferro. E com elas, as empresas siderúrgicas, que prometem emprego e riqueza para a região. Elas realizam a fusão e purificação do minério de ferro. A siderurgia se instalou graças ao consumo de carvão dos remanescentes de floresta. A maior parte da produção de carvão, por mais de dez anos, foi atrelada ao fenômeno desumano do trabalho escravo em carvoarias clandestinas. Várias denúncias tentaram frear a devastação da floresta e de vidas humanas para produção de ferro-gusa. Por décadas, as usinas siderúrgicas se sustentaram derrubando o que restava da Amazônia Oriental na região de Marabá-PA e Açailândia-MA.

O último ciclo econômico está transformando radicalmente os territórios, com o monocultivo de eucalipto para a produção de carvão vegetal, o "deserto verde". Consequências socioambientais: expulsão das famílias do campo, enfraquecimento dos projetos de agricultura familiar, contaminação por agrotóxicos e assoreamento das reservas de água no solo. A empresa VALE, que estabeleceu a infraestrutura de escoamento dos bens minerais a partir da garantia de "desenvolvimento" da inteira região de Carajás, multiplicou seu lucro. Mas a pobreza da região continua, e o ecossistema está submetido a crescente contaminação.

A história dos últimos sessenta anos dessa região negou o protagonismo das comunidades locais, ignorou vocações produtivas integradas ao território e alternativas aos ciclos de saque dos recursos locais. Mobilizou grandes massas de pessoas desenraizadas de suas regiões e forçadas a migrações em busca de trabalho não qualificado. Devolveu hoje territórios com uma urbanização descontrolada, um tecido social extremamente frágil e marcado pela violência. Em síntese: total ausência da cultura do cuidado para com o outro e a vida ${ }^{21}$.

${ }^{21}$ BOSSI, D. "Uma luta desigual”, pp. 19-20. 
Qual tem sido o trabalho dos missionários combonianos junto às populações atingidas pelo projeto de mineração de Carajás? A atuação se concentra nas comunidades do interior do Maranhão, promovendo iniciativas de agroecologia, atividades em mutirão e autoajuda entre famílias, aprendizado e intercâmbio a partir da experiência e das tradições locais. O trabalho é difícil, pois muitas pessoas, sobretudo os jovens, deixam-se fascinar pelos sonhos de consumo propostos pela economia de mercado. Capitulam diante das ofertas sedutoras (e enganosas) das empresas. Abandonam suas terras e migram para as cidades.

Que lições tirar com esta luta de resistência? Segundo Bossi,

Aprendemos nesses anos de caminhada a importância sagrada das poucas pessoas e comunidades que não se deixaram iludir e, fora da gramática do neodesenvolvimentismo, mostram que "há felicidade também por outras palavras", menos surpreendentes e mais cotidianas. (..) Aprendemos a não identificar as comunidades e as pessoas somente por aquilo a que se opõem, mas sobretudo por aquilo que defendem e que as fortalece: sua mais profunda identidade, seu estilo de vida, seus costumes e sonhos ${ }^{22}$.

Bossi afirma: o que dá razão (e gosto) à sua luta é o sabor da existência compartilhada com as pequenas comunidades nas zonas de sacrifício. Sentir na pele que os agentes pastorais não defendem simplesmente um princípio ou afirmam um modelo contra outro. E sim, estão lutando para que a vida se afirme acima das regras e dos projetos econômicos e políticos ${ }^{23}$.

Bossi não somente narra fatos, como também coloca seus sentimentos e convicções. Deixa-se tocar pela dor da terra e dos pobres. Isso marca a diferença, pois não se trata de uma mera apresentação de dados frios e pretensamente objetivos. E sim, o fruto de uma experiência de vida, de compromisso com a comunidade, da vivência da fraternidade, numa relação simultânea de aprender e ensinar, como discípulo missionário de Jesus.

Em cada mês de caminhada e compromisso contra os impactos da mineração, posso ter passado dias inteiros nas articulações estratégicas, na produção de artigos, pesquisas ou denúncias, na redação de cartilhas bonitas de educação popular ou na divulgação de campanhas sucedidas em favor de uma ou outra causa. Mas aquilo que mais permanece no fundo do

${ }^{22}$ BOSSI, D. "Uma luta desigual”, pp. 21,23.

${ }^{23}$ BOSSI, D. "Uma luta desigual”, pp. 23. 
coração e dá vontade e força de continuar é a memória de um encontro, a aliança com uma comunidade, a amizade selada com uma liderança que não desanima. A existência dos outros revitaliza a nossa também ${ }^{24}$.

A apresentação de casos reais, de forma articulada e mesclada com a indignação ética, na obra "Igreja e mineração", converge com a perspectiva adotada pelo Papa Francisco na Laudato Si. No capítulo I, ele oferece "uma resenha das questões que hoje nos causam inquietação e que já não se podem esconder debaixo do tapete" (LS 19), com a finalidade clara de despertar para o compromisso com a vida dos povos e do planeta.

O objetivo não é recolher informações ou satisfazer a nossa curiosidade, mas tomar dolorosa consciência, ousar transformar em sofrimento pessoal aquilo que acontece ao mundo e, assim, reconhecer a contribuição que cada um lhe pode dar (LS 19).

Egon Heck, ao refletir acerca da incursão das mineradoras em terras indígenas, cita o depoimento do líder indígena David Yanomami:

Se vocês brancos mostrarem um lugar onde os povos indígenas vivem realmente bem com a mineração, um lugar onde vivem com saúde, respeitando suas culturas, onde os brancos os ajudem de forma correta e não os enganem ao darem dinheiro, onde os indígenas não passem fome e onde não passem sede, se virmos esse lugar, do mesmo tamanho que a nossa floresta, nós, Yanomami, podemos voltar a discutir esse assunto" (in: Porantim - maio 2014) (..)

Para nós, desenvolvimento é ter nossa terra com saúde, permitindo que nossos filhos vivam de forma saudável num lugar cheio de vida...vocês não aprenderam com o que está acontecendo no mundo? Vocês ainda não aprenderam que esse tipo de desenvolvimento pode matar todos nós?"(in: Porantim - maio 2014) $)^{25}$.

Marina Rocha, coordenadora da CPT (Comissão Pastoral da Terra) da diocese de Juazeiro, norte da Bahia, narra os problemas provocados por um projeto de mineração de fosfato para a produção de fertilizantes químicos e a articulação em defesa das comunidades atingidas.

\footnotetext{
${ }^{24}$ BOSSI, D. "Uma luta desigual”, pp. 24.

${ }^{25}$ Citado por HECK, E. "Igrejas e mineração”, pp. 30-31.
} 
As pessoas estão mais sensibilizadas e passam a denunciar os impactos e a lutar por seus direitos, destacando como importante a defesa dos territórios. Os impactos percebidos são principalmente na saúde das pessoas, por causa do pó tóxico do fosfato, que causa doenças e suspeitas de mortes, falta de água e perda de animais. No momento, oito comunidades no entorno da mina lutam contra a ameaça de grilagem de uma área de 44.800 hectares (..) A assessoria jurídica da CPT atua no processo em defesa das comunidades. Existe também um grupo articulado que luta por direitos negados pela empresa na mitigação dos impactos ${ }^{26}$.

Os impactos negativos na saúde humana não somente dizem respeito à atividade de extração do minério, mas também ao transporte, sem falar da siderurgia. No caso da logística, o pó do minério transportado em vagões de trem se dissipa no ambiente, provocando poluição do ar. No relato a respeito do pó de minério que atinge a comunidade do assentamento Dorothy Stang, na região de Quatis (RJ), assim se pronuncia uma moradora:

Meu nome é Iva e eu estou aqui para falar sobre o minério. Esse trem passa aqui com os vagões todos descobertos e eu trouxe aqui para mostrar um mamão todo pintadinho. É o minério que fica na pele das frutas e depois estraga as frutas. O mamão e o maracujá também ficam todos pintadinhos. Agora imagina a gente, como estamos tomando essa água cheia de pó de minério, comendo essa comida com minério, respirando minério... Eu tenho um pigarro que não acaba. Posso tomar o que eu quiser, ele não sai. Eu creio que meu pulmão tá todo tomado de minério ${ }^{27}$.

Embora a legislação brasileira obrigue as mineradoras a ressarcir os danos e pagar de forma justa às comunidades em áreas de projetos mineradores, multiplicam-se as denúncias que estas empresas ignoram as reais necessidades das famílias, de sua cultura e de suas unidades produtivas. Veja-se o depoimento de Claúdio Evangelista, pequeno produtor rural da Mata da bananeira, no município de Patrocínio (MG), obrigado a deixar suas terras devido à construção de uma barragem de rejeitos da VALE Fertilizantes:

Nós queremos fazer negociação, sim. A primeira proposta que eles fizeram seria de uma área de mais de 40 hectares. Nós fomos lá e visitamos umas

\footnotetext{
${ }^{26}$ Citado por SIQUEIRA, R. "Mineração, desafio para um povo...”, pp. 55-56.

${ }^{27}$ Citado por CARDOSO, G; GONZAGA, N., "O trem passa, a sujeira fica..”, p. 79.
} 
duas ou três vezes. Mas a metade da terra é cascalho. O que eu vou fazer com uma área que é cascalho? Eu tenho 06 (seis) hectares de café, só terra vermelha. Eu nasci e me criei nessa região. Então, é justo eu deixar uma área minha, que é produtiva de café, 06 (seis) hectares de terra vermelha, e pegar uma área inferior, de cascalho? Cada dia que eu for sacudir a peneira lá, eu vou pegar cascalho. Então, nós não aceitamos! (..) Não sou obrigado a sair para a VALE ir ganhando milhões e milhões de dinheiro e dar minha terra de graça. Eu tenho cinco pessoas dentro da minha casa e agora tem minha sogra. Como que a gente vai viver? ${ }^{28}$

Estes depoimentos corroboram para uma análise que supera os meros dados estatísticos. Como se nota, trata-se de pessoas, comunidades e áreas ambientais com qualidade de vida ameaçada. Um dos méritos da articulação "Igrejas e mineração" consiste em escutar a parcela invisivel da população atingida pela mineração, que não encontra eco nem na mídia convencional, nem nas novas mídias e nas redes sociais. Dar a voz aos sem voz, que trazem consigo o grito social e ambiental.

A unidade entre a questão ambiental e a social foi enfatizada várias vezes na Laudato Si.

$\mathrm{O}$ ambiente humano e o ambiente natural degradam-se em conjunto; e não podemos enfrentar adequadamente a degradação ambiental, se não prestarmos atenção às causas que têm a ver com a degradação humana e social. De fato, a deterioração do meio ambiente e a da sociedade afetam de modo especial os mais frágeis do planeta (LS 48)

(..) uma verdadeira abordagem ecológica sempre se torna uma abordagem social, que deve integrar a justiça nos debates sobre o meio ambiente, para ouvir tanto o clamor da terra como o clamor dos pobres (LS 49)

\section{A leitura crítica}

A articulação "Igrejas e mineração" realiza uma leitura crítica acerca da mineração. Não somente aborda os problemas socioambientais decorrentes de atividade mineradora, mas também a situam no horizonte de um quadro mais amplo. Tal reflexão combina os testemunhos de pessoas e grupos que sofrem a ação da mineração com uma análise crítica, utilizando categorias econômicas e geopolíticas.

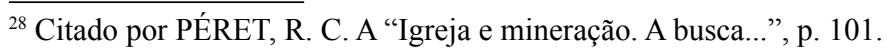


A mineração, como processo extrativista, insere-se num projeto mais amplo de sociedade, classificado como neocolonial, explorador e insustentável, com profundas e duradouras consequências sobre o ambiente.

Do ponto de vista das populações indígenas, a mineração constitui uma ameaça permanente, porque rompe a unidade de relação entre os seres humanos e a natureza. No dizer de David Yanomami: "Não pensamos as coisas de forma dividida; pensamos na nossa terra-floresta como um todo. Se vocês destruírem o que está abaixo do solo, tudo que está acima também sofrerá"29. Mais. O movimento indigenista, com o apoio do CIMI, tem denunciado sistematicamente as invasões de garimpeiros e mineradoras e os impactos negativos dessas presenças. As elites políticas e econômicas ligadas ao setor mineral mostram voracidade com relação ao potencial de minérios em territórios indígenas. Nas últimas décadas, são inúmeras as propostas de escancarar as terras indígenas, vindas do poder Legislativo ou do Executivo ${ }^{30}$.

Houve um enorme expansionismo minerário no Brasil. Já são 3.000 minas e 9.000 mineradoras, sem contar centenas, se não milhares, de garimpos ilegais e clandestinos. Segundo o Portal Brasil, o setor mineral, que compreende mineração, metalurgia e transformação mineral de não metálicos, emprega cerca de 200 mil trabalhadores, e é responsável por 4\% do PIB. No estado da Bahia, que tem a maior diversidade minerária do Brasil, multiplicam-se os empreendimentos minerários e as obras de infraestrutura, públicas ou financiadas com recursos públicos. Ali operam 340 empresas de mineração, em 100 municípios, que geram apenas 8.000 empregos $^{31}$.

A mineração ameaça os mananciais de água, pois um território ferrífero é também aquífero. O grande argumento em defesa da mineração consiste em que ela gera progresso, move a economia, cria empregos e melhora as condições de vida da população. No entanto, a realidade tem se mostrado outra, segundo a análise dos autores de "Igreja e mineração". Bruno Milanez assim resume os principais impactos socioambientais da mineração:

- A abertura e a ampliação das minas a céu aberto avançam sobre comunidades rurais, populações tradicionais e áreas preservadas;

- À medida que se intensifica a extração mineral, aumenta a necessidade de espaço para a construção de barragens de rejeitos. Assim,

\footnotetext{
${ }^{29}$ Citado por HECK, E. "Igrejas e mineração", p. 2.

${ }^{30}$ Cf. HECK, E. "Igrejas e mineração", pp. 49-51.

${ }^{31}$ SIQUEIRA, R. “Mineração, desafio para um povo...”, p. 50.
} 
restringe-se o uso do território para outras atividades sociais ou econômicas.

- Devido à insalubridade e à periculosidade do trabalho em mineração, cresce o número de acidentes de trabalho e de adoecimento laboral;

- O aumento da profundidade das cavas obriga as empresas a bombear água e rebaixar o lençol freático, causando impactos, como o desaparecimento de nascentes ou inviabilização de poços existentes.

- Quando as minas se encontram próximas a centros urbanos, a intensificação da produção implica no aumento da emissão de material particulado (pó de minério) e na piora da qualidade do $\operatorname{ar}^{32}$.

- Por fim, como a maior parte do minério extraído é exportada, existe a intensificação do uso dos sistemas de transporte, em particular ferrovias, com o aumento do fluxo de trens e do consequente risco de acidentes e atropelamentos, particularmente em áreas rurais, como nos estados do Pará e Maranhão.

Diante desse cenário preocupante, questiona-se onde estaria a legislação ambiental e os órgãos estatais de controle, de forma a garantir que a mineração se efetive de maneira equilibrada. Ou, como alardeiam as empresas de mineração, de forma sustentável. Em primeiro lugar, sabe-se que o projeto de mineração deve ser submetido a um estudo sobre suas prováveis consequências (EIA: estudo de impacto ambiental). E as comunidades locais precisam ser ouvidas. O órgão regulador do estado ou da federação emite então um RIMA (relatório de impacto sobre o meio ambiente), seguida de uma licença de implantação do empreendimento (LI). E, por fim, a licença de operação (LO) ${ }^{33}$. A grande questão é que os pareceres técnicos subestimam os impactos negativos e valorizam demasiadamente os efeitos positivos, sobretudo os benefícios econômicos para as comunidades locais e o progresso para o país.

Todo EIA consegue provar a viabilidade econômica, a sustentabilidade

\footnotetext{
${ }^{32}$ MILANEZ, B. "Mineração e Igreja: contextos...”, pp. 121-122.

33 Legislação em vigor quando se escreveu este artigo, conforme a resolução 237/97 do CONAMA. No entanto, um grupo de políticos ligados ao agronegócio e às mineradoras se mobiliza para levar à votação a PEC 65/2012, que segundo seus defensores, levaria a uma "simplificação" do processo de licenciamento ambiental. Na prática, facilita a implantação de empreendimentos que forte impacto ambiental negativo, sem o devido controle da sociedade civil. Para acompanhar o desenvolvimento da questão, ver a página WEB do Instituto Socioambiental (ISA): <https://www.socioambiental.org/pt-br>. Acesso em 10 de junho de 2016.
} 
ambiental e a equidade social de cada projeto. Um conjunto abalizado de estudiosos, muito bem pagos pela empresa, despeja na nossa frente milhares de páginas, gráficos, mapas, imagens que nossas comunidades não têm o tempo de estudar e que nos fazem sentir ignorantes e impotentes diante de tanta clareza a respeito da indiscutível importância e necessidade do projeto. Aliás, um ponto comum a todos os EIAs é: como ficaria a sociedade sem este projeto? E a resposta é sempre a mesma: ai de nós se ele não for implantado! $!^{34}$

As empresas e os poderes locais se empenham em cooptar as lideranças sociais e torná-las facilitadoras do projeto. Argumenta-se que os impactos ambientais negativos seriam compensados com impactos sociais positivos. Galazzi desmistifica a lógica do discurso minerador, ao mostrar que a folha de pagamento e os impostos fazem parte de qualquer projeto lucrativo; não são um favor para a população. Para as empresas, folha e impostos são contabilizados como passivos. Porque a sociedade deve contabilizá-los como ativos? Então, vários impostos deixam de ser cobrados com a justificativa de facilitar a viabilidade e a competitividade do projeto. Além disso, as medidas compensatórias (prometidas e parcialmente realizadas) são abatidas do imposto de renda devido, por serem consideradas de importância social. E as comunidades locais não participam da repartição do lucro da empresa ${ }^{35}$.

Os autores da obra denunciam as maquinações em andamento, visando mudanças na legislação, de forma a favorecer ainda mais as mineradoras. A atual legislatura pretende modificar o marco legal da mineração, inclusive aquela que diz respeito às terras indígenas. Tramita no congresso o "código da mineração". Segundo Milanez, muitos dos impactos acima elencados e dos conflitos deles resultantes seriam mitigados se o sistema de licenciamento ambiental no país fosse efetivo. Mas, nos últimos anos há uma crescente precarização das agências estaduais de meio ambiente, flexibilização da legislação ambiental e deturpação da legislação existente ${ }^{36}$.

A mineração destinada à exportação ganha destaque no atual momento histórico. Não somente o Brasil tem vivido o que Boaventura Souza Santos chama de "maldição da abundância" ${ }^{37}$. Um país, rico em recursos minerais,

\footnotetext{
${ }^{34}$ GALAZZI, S. "Vida, Bíblia e mineração", pp. 96-97.

${ }^{35}$ GALAZZI, S. "Vida, Bíblia e mineração", p. 97.

${ }^{36}$ MILANEZ, B. "Mineração e Igreja: contextos...", pp. 123-124.

${ }^{37}$ Citado por SIQUEIRA, R. "Mineração, desafio para um povo...”, pp. 57-58.
} 
mais se deteriora do que se beneficia de sua exploração, se ela não é realizada de forma socialmente responsável e ecologicamente sustentável. Dentre os muitos riscos, se destacam: crescimento do PIB sem acompanhar o desenvolvimento social; corrupção generalizada da classe política para defender os seus interesses privados; aumento em vez de redução da pobreza; concentração de renda; destruição ambiental e danos às populações onde se encontram os recursos naturais; criação de uma cultura consumista, imposta como ideologia a toda a sociedade; uso do aparato de segurança para perseguir aos que se opõem às mineradoras.

Há uma questão de paradigma, que subjaz à lógica de exploração contínua da mineração. A civilização contemporânea, com seu forte controle da natureza e alto grau de urbanização, ignora que, em última instância, os seres humanos dependem da natureza para viver. Deve-se criticar o caráter puramente utilitário da relação com o ecossistema. Na visão capitalista clássica, considera-se a destruição do meio ambiente somente como um dos "danos colaterais", a serem reduzidos na medida do possível. Ou ainda, como "fatores externos", que não entram nos cálculos das planilhas de custos e investimentos. Um novo paradigma, ora em emergência, redefine a relação com a Terra, "não como exploração, enquanto fonte de recursos naturais capazes de ser reduzidos ao estatuto de mercadorias, mas como a fonte de toda a vida, em uma atitude de respeito à sua capacidade de regeneração física e biológica" ${ }^{38}$.

No capítulo III da Laudato Si o Papa Francisco propõe a seus interlocutores uma reflexão sobre a raiz humana da crise ecológica, que segundo ele, se radica na globalização do paradigma tecnocrático. Trata-se de uma cosmovisão, um modelo de um modelo de compreensão, "homogêneo e unidimensional" (LS 106), que transforma o ser humano em um déspota da criação.

\begin{abstract}
(..) agora, o que interessa é extrair o máximo possível das coisas por imposição da mão humana, que tende a ignorar ou esquecer a realidade própria do que tem à sua frente. Por isso, o ser humano e as coisas deixaram de se dar amigavelmente a mão, tornando-se controversas. Daqui passa-se facilmente à ideia dum crescimento infinito ou ilimitado (..). Isto supõe a mentira da disponibilidade infinita dos bens do planeta, que leva a «espremê-lo» até ao limite e para além do mesmo (LS 106).
\end{abstract}

Tal paradigma domina na economia e na política. O desenvolvimento tec-

${ }^{38}$ HECK, E. "Igrejas e mineração", p. 43. 
nológico se realiza em função do lucro, sem prestar atenção às consequências negativas para o ser humano e o planeta (cf. LS 90). Como alternativa a esta "lógica globalizada" Francisco propõe o cultivo da "cultura ecológica", articulando (..) um olhar diferente, um pensamento, uma política, um programa educativo, um estilo de vida e uma espiritualidade que oponham resistência ao avanço do paradigma tecnocrático" (LS 111) 39 . Isso implica "limitar a técnica, orientá-la e colocá-la ao serviço doutro tipo de progresso, mais saudável, mais humano, mais social, mais integral" (LS 112). Tal postura não consiste numa anacrônica e idealizada volta ao passado, que negaria a contribuição da ciência e de técnica. E sim "olhar a realidade doutra forma, recolher os avanços positivos e sustentáveis e ao mesmo tempo recuperar os valores e os grandes objetivos arrasados por um desenfreamento megalômano" (LS 114).

\section{Visão bíblico-teológica}

Como entender esta dura realidade à luz da fé cristã? Os agentes de pastoral da Articulação "Igrejas e mineração" fazem uma leitura teológico-pastoral que contempla vários aspectos: amor ao Deus da vida, compromisso com os pobres e a Terra, solidariedade e resistência.

O biblista Marcelo Barros ${ }^{40}$ apresenta uma síntese da visão bíblica acerca da relação entre o ser humano e o planeta, como pano de fundo para compreender a postura da Igreja em relação à mineração. Resumidamente:

(1) Os seres humanos fazem parte de uma comunidade mais ampla e com a qual Deus fez uma permanente aliança de amor (Gn 9, 8-17), que dura enquanto o mundo existir. Não pertence em si ao Antigo Testamento. Fundamenta assim uma visão teológica que cosmoteândrica (R. Panikkar), porque une cosmos, Deus e o ser humano.

(2) Segundo a bíblia, a criação não existe para o ser humano, e sim para a glória de Deus. E essa glória significa a manifestação de Sua presença. Então, o universo e a terra são como sacramentos, expressões vivas da presença divina e do seu amor.

(3) A salvação se destina a toda a criação (Rm 8, 20-21). Há uma inter-

${ }^{39}$ Ver o elucidativo artigo de OLIVEIRA, M. "O paradigma tecnocrático". In: MURAD, A; TAVARES, S. S. Cuidar da Casa Comum. Chaves de leitura teológicas e pastorais da Laudato Si. São Paulo: Paulinas, 2016, pp. 129-145.

${ }^{40}$ BARROS, M. “A aliança com a criação”, pp. 126-127. 
relação ecológica. O projeto divino, que os evangelhos sinóticos chamam de "reinado divino", ou "reino de Deus" não diz respeito somente à humanidade e sim a toda a terra e ao Cosmo.

(4) Deus confiou à humanidade a missão de salvaguardar a Terra e seus ecossistemas. Em uma sociedade no qual ela está acorrentada e reduzida a mercadoria, é função da humanidade libertar-se e libertar a Terra. Para Teologia da Libertação, anunciar um Deus comprometido com a libertação dos oprimidos, inclui o cuidado com o solo, a água e todo o universo.

(5) Jesus ressuscitado recapitula toda a criação. Restitui ao universo um equilíbrio que o pecado quebrara. Cristo restaura e plenifica tudo o que existe (Cf. Rom 8, 20-22; Col 1, 15-17; Jo 1, 1-5). É cabeça, base de todo cosmos reconciliado com Deus. Paulo chama de "plenitude", o universo cristificado, cheio da presença amorosa de Deus.

(6) Conforme o quarto evangelho, no domingo da ressurreição, primeiro dia da nova criação, Jesus sopra sobre seus discípulos reunidos, lhes dá o seu Espírito como novo sopro de vida. O Espírito Mãe renova a face da terra e é princípio de uma nova relação entre a comunidade humana e o universo que nos cerca.

A reflexão de Marcelo Barros encontra eco e legitimidade na Doutrina Social da Igreja, conforme é explicitado no capítulo II da Laudato Si, intitulado "O Evangelho da criação". Deste belo texto, destacamos:

- As narrações da criação no livro do Gênesis "sugerem que a existência humana se baseia sobre três relações fundamentais intimamente ligadas: as relações com Deus, com o próximo e com a terra" (LS 66).

- Há uma relação de reciprocidade responsável entre o ser humano e a natureza. Cada comunidade pode tomar da terra aquilo de que necessita, e também deve protege-la e garantir a continuidade da sua fertilidade para as gerações futuras. Em última análise, ao Senhor pertence a terra e tudo o que nela existe (S1 24,1; Dt 10, 14). Deus proíbe-nos toda a pretensão de posse absoluta (Lv 25, 23) (LS 67).

- Os outros seres vivos tem um valor próprio diante de Deus (LS 69). Eles não são "meros objetos submetidos ao domínio arbitrário do ser humano" (LS 82).

- Nas narrações bíblicas “já está contida a convicção atual de que tudo 
está inter-relacionado e o cuidado autêntico da nossa própria vida e das nossas relações com a natureza é inseparável da fraternidade, da justiça e da fidelidade aos outros" (LS 70). (Ver também LS 91)

- A criação é sistema aberto (LS 79). O Espírito de Deus encheu o universo de potencialidades que permitem que, do próprio seio das coisas, brote sempre algo de novo (LS 80).

- Reconhecer o valor e a fragilidade da natureza, como também as capacidades que o Criador nos deu, permite-nos acabar com o mito moderno do progresso material ilimitado. Um mundo frágil, com um ser humano a quem Deus confia o cuidado, interpela-nos a orientar, cultivar e limitar o nosso poder em relação ao mundo (LS 78).

- O meio ambiente é um bem coletivo, patrimônio de toda a humanidade e responsabilidade de todos. Quem possui uma parte é apenas para a administrar em benefício de todos (LS 95).

Segundo Sandro Galazzi, a mineração pode ser uma benção, se compreendida à luz da espiritualidade bíblica, centrada na experiência da libertação do Egito, da aliança de Deus com seu povo, da Boa Nova de Jesus e do Reino de Deus ${ }^{41}$. Faz parte da promessa e da terra prometida, contanto que realizada no âmbito da fidelidade ao Deus da Vida (Dt 8,1; Jo 10,10). A terra somente será terra prometida e não maldita, se respondermos aos apelos de Deus: guardar seus mandamentos, andar nos seus caminhos, respeitá-lo e amá -lo (Dt 8,6; Jo 15). Toda a atividade humana, inclusive a mineração, só adquire sentido e valor quando realizada nesta perspectiva.

O livro do Apocalipse sinaliza um horizonte aberto à nossa frente, que se torna utopia e paradigma da caminhada atual: a nova Jerusalém (Ap 21,1021), resplandecente de luz, cheia de pedras preciosas (jaspe, safira, esmeralda, ametista, ouro...). Propositalmente, faltam nela o ferro, o cobre e a prata, que eram utilizados para o trabalho escravizador, o comércio do império e a guerra. Deus estará para sempre com o seu povo. Não haverá dor, nem lágrimas (Ap 21,3-4). A nova Jerusalém seria assim o símbolo do projeto de uma nova sociedade: o reino de Deus que supera o reino dos césares, do mercado e do militarismo. À luz desta profecia se esquadrinham as experiências atuais no enfrentamento dos conflitos provocados pela mineração ${ }^{42}$.

${ }^{41}$ Cf. GALAZZI, S. "Vida, Bíblia e mineração", pp. 85-87.

${ }^{42}$ Cf. GALAZZI, S. "Vida, Bíblia e mineração”, pp. 91-92. 
Conforme Galazzi, a opção clara pela vida dos pobres e da Terra é o filtro pelo qual se avalia qualquer projeto econômico, sobretudo quando se autojustifica como "crescimento", "desenvolvimento" e "progresso". Seria ilegítimo, ilusório e perverso, quando provoca a concentração da riqueza, a devastação ambiental e a violência contra a pessoa. Deus não quer isso, não! Tal posição tem suas raízes na certeza que o planeta e suas riquezas são para todos que nela habitam e para todas as gerações ${ }^{43}$. Galazzi contrapõe a expressão "casa comum", atribuída ao nosso planeta, à "casa grande", símbolo do poder colonial, que gera escravos e submete o meio ambiente. E daí tira uma importante conclusão teológica.

Ecologia e economia tem a mesma origem na palavra "casa" (oikos): de que casa falamos (logos) e quais são as suas regras (nomos). Nós acreditamos que não podem conviver uma casa-grande e uma senzala. Cremos na tenda comum, onde todos e todas possam sentar ao redor da mesma mesa, partilhando do mesmo prato. Ecologia não pode ser reduzida a discutir o que fazer com o "quintal". Podemos correr o risco de preservar o quintal em benefício só da casa-grande, deixando a senzala ao Deus dará. Da ecologia (de que casa estamos falando) depende a economia (quais as regras da nossa casa) e depende também, a teologia (de que Deus estamos falando). Antes de sermos portadores de um projeto concreto, somos movidos por este critério de fidelidade. A nossa casa, a casa que o nosso Deus quer e preparou para nós é a cidade santa. Não aceitaremos regras que façam de nossa casa uma casa-grande ${ }^{44}$.

E novamente, volta a pergunta: Se Deus é fiel a seu povo, porque, no confronto com poderosas mineradoras, as comunidades locais e o meio ambiente quase sempre saem perdendo? Galazzi conclui sua reflexão recorrendo à imagem do sonho do imperador Nabucodonosor, narrado em Dan 2,32-33. Trata-se de uma gigantesca e temível estátua, que simboliza o então invencível poder babilônico. O império se autoproclama como deus, a ser adorado e reverenciado (Dn 3,4-6). Embora a cabeça seja de ouro e o peito, de prata, seus pés são frágeis, pois estão constituídos de uma amálgama de ferro e barro. Sem expectativas milagrosas, as comunidades que enfrentam os projetos mineradores creem na força do Espírito de Deus, em meio a derrotas e imensas dificuldades.

${ }^{43}$ GALAZZI, S. "Vida, Bíblia e mineração", p. 93.

${ }^{44}$ GALAZZI, S. "Vida, Bíblia e mineração", p. 93. 
Quando virá a pedra que esmiuçará a estátua, aparentemente indestrutível? (Dn 2,45). Nesta luta desigual pela justa social e ambiental, recordam-se as figuras bíblicas do fraco que vence o forte, pela ação de Deus, como a pedra de Daniel, a mão de Judite, o fogo de Elias, a baladeira de Davi, a vara de Moisés ${ }^{45}$.

Qual é a esperança de um povo que luta tanto e consegue vitórias tão pequenas? Bossi afirma, resumidamente: “nossa agonia é nossa vitória!”. O agente de pastoral aprende do povo uma enorme resistência à dor, vivida $\mathrm{e}$ celebrada de forma coletiva, em comunidade. De certa forma, as pessoas se aproximam na dor, que alimenta a solidariedade. Os cristãos comprometidos com causas socioambientais sentem-se vinculados "num pacto de fidelidade e agonia (luta) contra as forças que ameaçam a vida". A eucaristia, renovação da vida, morte e ressurreição de Jesus nutre a esperança, contra todas as evidências em contrário. Na impotência da cruz se desvela uma força indescritível. $\mathrm{Na}$ eucaristia anuncia-se a vitória do Reino, ainda tão fragmentada na conturbada história humana.

Acontece-me, com certa frequência, de celebrar a eucaristia em lugares de particular sofrimento e injustiça ambiental. Levanto o cálice, no meio do pequeno grupo que concelebra, e vejo fora da porta da igreja a fumaça densa da poluição siderúrgica que mata crianças e idosos da comunidade. Ou sinto o barulho ensurdecedor do trem da Vale que passa a cada hora e 'sequestra o tempo' da comunidade, bloqueando atividades e mobilidade. Nesses momentos de aparente impotência, recolhe-se a luta e a agonia de muitas pessoas e comunidades em todo canto do mundo, dores do parto desse cosmos em construção. Renova-se a solidariedade e o compromisso, o sentido de um 'nós' que existe e se fortalece na comunhão $0^{46}$.

\section{Critérios pastorais}

Segundo Ari dos Reis, tomar posição diante da mineração é uma atitude de serviço que a Igreja presta ao povo brasileiro ${ }^{47}$. Tal tema, acentuado na Campanha da Fraternidade de 2015, convida à reflexão sobre a relação entre Igreja e sociedade, com o lema: "Eu vim para servir" (Mc 10,45).

\footnotetext{
${ }^{45}$ GALAZZI, S. "Vida, Bíblia e mineração", p. 9.

${ }^{46}$ BOSSI, D. "Uma luta desigual”, p. 26.

${ }^{47}$ REIS, A. A.“A Igreja diante da mineração”, pp. 128-129. O autor exerceu a função de assessor da CNBB, na comissão episcopal para o serviço da caridade, justiça e paz durante vários anos.
} 
A dimensão servidora faz parte da ação evangelizadora da Igreja. Evangelizar e servir são dimensões de um mesmo processo e estão em sintonia com o Reino querido por Jesus. O mandato missionário (Mt 28,19-20), iniciado pela decisão do Filho de encarnar-se no mundo (Jo 1,1) é seguimento, o discipulado. Na perspectiva de recuperar a dignidade dos homens e mulheres atingidos pela doença, prisão, fome ou miséria (Lc 4,16-20).

A tarefa primeira da Igreja, a evangelização, visa tornar o Reino de Deus presente no mundo (EG. 176), o que demanda compromissos e consequências: "a Igreja é convocada a ser advogada da Justiça e defensora dos pobres diante das intoleráveis desigualdades sociais e econômicas que clamam aos céus" (DAp 395). Se a tarefa da Igreja é o anúncio do Reino, e este anúncio tem um conteúdo social (EG 177), cabe também denunciar todas as situações que se configuram como anti-Reino pelo fato de ameaçar a dignidade das pessoas e o equilíbrio do espaço de vida, a casa de toda a humanidade ${ }^{48}$.

A presença da Igreja na reflexão sobre a mineração é parte desta índole e se desdobra em algumas iniciativas constantes do seu horizonte missionário. A problemática da mineração impele a Igreja a concretizar o princípio do serviço, destacado na Campanha da Fraternidade, vivenciado por Jesus na sua missão (Mc 1, 29ss) e colocado como regra de vida para os discípulos (Mc 10,45; Jo 13,1ss). Tal empenho, segundo Ari, se baseia nos princípios de: serviço à vida em toda a sua extensão, primazia do ser humano sobre o econômico, preocupação ambiental, e teologia do cuidado $^{49}$.

No Capítulo V da Encíclica Laudato Si (Algumas linhas de orientação e ação), o Papa Francisco dedica os parágrafos 182 a 188 aos chamadas "grandes projetos", com critérios concretos para orientar a implantação de empreendimentos de alto impacto ambiental negativo, como os da mineração, centrais hidroelétricas e rodovias ${ }^{50}$. São eles:

- A previsão do impacto ambiental dos empreendimentos e projetos requer processos políticos transparentes e dialogais (LS 182).

- Um estudo de impacto ambiental deve inserir-se desde o princípio da elaboração de um projeto produtivo ou de qualquer política, plano ou

\footnotetext{
${ }^{48}$ REIS, A. A.“A Igreja diante da mineração”, p. 129.

${ }^{49}$ REIS, A. A.“A Igreja diante da mineração”, pp. 129-131.

${ }^{50}$ Parece que os parágrafos 182-188 foram redigidos a partir da contribuição de Dom Erwin Käutler, então bispo da prelazia do Xingu, que esteve teceu duras críticas à forma como foi implantado o empreendimento da usina de Belo Monte.
} 
programa. Realizado de forma interdisciplinar, transparente e independente de qualquer pressão económica ou política. Deve aparecer unido à análise das condições de trabalho e dos possíveis efeitos na saúde física e mental das pessoas, na economia local, na segurança (LS 183).

- É necessário alcançar consenso entre os vários atores sociais, que podem trazer diferentes perspectivas, soluções e alternativas. No debate, terão lugar privilegiado os moradores locais, que se interrogam sobre o que desejam para si e para os seus filhos e podem ter em consideração as finalidades que transcendem o interesse económico imediato (LS 183).

- A participação requer que todos sejam adequadamente informados sobre os vários aspectos e os diferentes riscos e possibilidades, e não se reduza à decisão inicial sobre um projeto, mas implique também ações de controle ou monitoramento constante (LS 183).

- Quando surgem eventuais riscos para o meio ambiente que afetam o bem comum presente e futuro, exige-se que as decisões sejam baseadas num confronto entre riscos e benefícios previsíveis para cada opção alternativa possível. Isto vale sobretudo quando um projeto pode causar incremento na exploração dos recursos naturais, nas emissões ou descargas, na produção de resíduos, ou então uma mudança significativa na paisagem, no habitat de espécies protegidas ou num espaço público (LS 184).

- Na discussão sobre um empreendimento, deve-se colocar uma série de perguntas, para discernir se esse levará a um desenvolvimento integral: Para que fim? Por qual motivo? Onde? Quando? De que maneira? A quem ajuda? Quais são os riscos? A que preço? Quem paga as despesas e como o fará? Neste exame, há questões prioritárias. Por exemplo, a água é um recurso escasso e indispensável, sendo um direito fundamental que condiciona o exercício doutros direitos humanos. Isto está, sem dúvida, acima de toda a análise de impacto ambiental de uma região (LS 185).

- O princípio de precaução permite a proteção dos mais fracos, que dispõem de poucos meios para se defender e fornecer provas irrefutáveis. Se a informação objetiva leva a prever um dano grave e irreversível, mesmo que não haja uma comprovação indiscutível, o projeto deverá ser suspendido ou modificado (LS 186). 
- Se aparecem novos elementos de juízo a partir de ulteriores dados informativos, deverá haver uma nova avaliação com a participação de todas as partes interessadas. $\mathrm{O}$ resultado do debate pode ser: não avançar num projeto, modifica-lo ou elaborar propostas alternativas (LS 187).

- Há discussões sobre problemas relativos ao meio ambiente, onde é difícil chegar a um consenso. A Igreja não pretende definir as questões científicas nem substituir-se à política. Ela se envolve em debate honesto e transparente, para que o bem comum esteja acima das necessidades particulares ou das ideologias (LS 118).

Nota-se que há uma distância enorme entre os critérios estabelecidos pelo Papa Francisco, referendados também por documentos intergovernamentais e de organizações internacionais, e os processos de implantação e implementação de mineração no nosso país. As experiências relatadas no livro "Igreja e mineração" testemunham como é necessária a presença da comunidade eclesial nesta área. Mais. Que a sociedade tome consciência dos efeitos danosos da mineração insustentável, e que haja política pública eficaz de controle e monitoramento.

\section{Conclusão aberta}

A articulação "Igrejas e mineração" responde, de maneira atual, à proposta de Gaudium et Spes, do Vaticano II. A partir dos testemunhos dos membros das comunidades atingidas e da reflexão dos agentes de pastoral, percebe-se uma grande sintonia com as alegrias, tristezas, esperanças e crises de seres humanos contemporâneos, sobretudo os mais frágeis. Manifesta-se o desejo do Concílio de estreitar-se o diálogo da Igreja com o mundo. Realiza-se o mandato expresso na Campanha da Fraternidade de 2015. A Igreja serve à sociedade, em vista da justiça e da sustentabilidade.

Desvela-se também um grande amor à Terra, nossa casa comum. Em meio a muitos conflitos, inerentes a este tipo de compromisso socioambiental, cultivam-se as virtudes teologais fundamentais. $\mathrm{O}$ amor se traduz sobremaneira na solidariedade com os pequenos e com a Terra ferida. A esperança se recria a cada luta, mesmo diante da impotência e da agonia. E a fé no Deus da vida nutre as comunidades peregrinas e fatigadas, a caminho do "novo céu e da nova terra". 
Encerramos nossa reflexão com as palavras estimuladoras do Papa Francisco, ao concluir a Laudato Si:

Caminhemos cantando; que as nossas lutas e a nossa preocupação por este planeta não nos tirem a alegria da esperança. Deus, que nos chama a uma generosa entrega e a oferecer-Lhe tudo, também nos dá as forças e a luz de que necessitamos para prosseguir. No coração deste mundo, permanece presente o Senhor da vida que tanto nos ama. Não nos abandona, não nos deixa sozinhos, porque Se uniu definitivamente à nossa terra e o seu amor sempre nos leva a encontrar novos caminhos. Que Ele seja louvado! (LS 244-245)

\section{Referências bibliográficas}

BARROS, M. "A aliança com a criação. Um olhar bíblico-teológico". MURAD, A; BOSSI, D. (Orgs.). Igreja e mineração. Em defesa da vida e dos territórios. Brasília: CNBB, 2015, pp. 125-127.

BOSSI, D. "Uma luta desigual. Que vitória é possível? Experiências e reflexões no enfrentamento aos impactos da mineração". In: MURAD, A; BOSSI, D. (Orgs.). Igreja e mineração. Em defesa da vida e dos territórios. Brasília: CNBB, 2015, pp. 15-27.

Cadernos IHU em Formação 48 (2015): "Mineração e o impulso à desigualdade: impactos ambientais e sociais". Disponível em: $<$ http://ihu.unisinos. $\mathrm{br} /$ cadernos-ihu-em-formacao/550361-48o-edicao-mineracao-e-oimpulso-a-desigualdade-impactos-ambientais-e-sociais $>$. Acesso em 09 de junho de 2016.

CARDOSO, N., GONZAGA, G. "O trem passa, a sujeira fica. Tampa o trem! Conversa com o assentamento Irmã Dorothy”. In: MURAD, A; BOSSI, D. (Orgs.). Igreja e mineração. Em defesa da vida e dos territórios. Brasília: CNBB, 2015, pp. 73-84.

GALAZZI, S. "Vida, Bíblia e Mineração". In: MURAD, A; BOSSI, D. (Orgs.). Igreja e mineração. Em defesa da vida e dos territórios. Brasília: CNBB, 2015, pp. 1-9.

HECK, H. "Igrejas e Mineração. Um olhar a partir dos Povos Indígenas". In: MURAD, A; BOSSI, D. (Orgs.). Igreja e mineração. Em defesa da vida e dos territórios. Brasília: CNBB, 2015, pp.1-12. 
MILANEZ, B. “O Brasil no contexto da mineração global (Mineração e Igreja: contexto e critérios)". In: MURAD, A; BOSSI, D. (Orgs.). Igreja e mineração. Em defesa da vida e dos territórios. Brasília: CNBB, 2015, pp. 119-124.

MURAD, A; BOSSI, D. (Orgs.). Igreja e mineração. Em defesa da vida e dos territórios. Brasília: CNBB, 2015 (publicação da Comissão Episcopal para o serviço da Caridade, Justiça e Paz).

MURAD, A; BOSSI, D. "O que a Igreja tem a ver com a mineração?” In: MURAD, A; BOSSI, D. (Orgs.). Igreja e mineração. Em defesa da vida e dos territórios. Brasília: CNBB, 2015, pp. 7-13.

MURAD, A; TAVARES, S.S, Cuidar da Casa Comum. Chaves de leitura teológicas e pastorais da Laudato Si. São Paulo: Paulinas, 2016.

MURAD, A. (Org.). Ecoteologia: um mosaico. São Paulo: Paulus, 2016.

OLIVEIRA, P. A. R; SOUZA, J. A. (Orgs.). Consciência planetária e religião: desafios para o século XXI. São Paulo: Paulinas, 2009.

Página WEB do Observatorio de conflictos mineros de América Latina (OCMAL): <http://www.conflictosmineros.net/>. Acesso em 09 de junho de 2016.

Página WEB da Articulação "Justiça nos Trilhos": <http://www. justicanostrilhos.org/>. Acesso em 09 de junho de 2016.

Papa FRANCISCO. Carta Encíclica Laudato Si. Sobre o cuidado da Casa Comum. São Paulo: Paulinas, 2015.

PÉRET, R. C. A. "Igreja e Mineração - A busca da mística de resistência e vida”, In: MURAD, A; BOSSI, D. (Orgs.). Igreja e mineração. Em defesa da vida e dos territórios. Brasília: CNBB, 2015, pp. 101-117.

REIS, A.A. "A Igreja diante da mineração. Critérios pastorais”. In: MURAD, A; BOSSI, D. (Orgs.). Igreja e mineração. Em defesa da vida e dos territórios. Brasília: CNBB, 2015, pp. 127-131.

Revista Porantim 380 (nov 2015): “As veias abertas nas terras indígenas". Disponível em: <http://www.cimi.org.br/pub/Porantim/2015/Porantim 380_nov2015.pdf $>$. Acesso em 09 de junho de 2016.

SIQUEIRA, R. "Mineração: desafio para um povo que caminha na fé", In: MURAD, A; BOSSI, D. (Orgs). Igreja e mineração. Em defesa da vida e dos territórios. Brasília: CNBB, 2015, pp. 47-59. 
VALENTIM, T. “A peleja da vida contra o urânio". In: MURAD, A; BOSSI, D. (Orgs). Igreja e mineração. Em defesa da vida e dos territórios. Brasília: CNBB, 2015, pp. 61-71.

Vídeo: Iglesias y minería, Igreja e mineração na América Latina (2015). Disponível em: <https://www.youtube.com/watch?v=Icr28HdyCfo>. Acesso em 09 de junho de 2016.

\begin{abstract}
Afonso Murad
Doutor em Teologia pela Universidade Gregoriana (Roma)

Professor de Teologia na Faculdade Jesuíta de Filosofia e Teologia (FAJE) Belo Horizonte / MG - Brasil E-mail: murad4@hotmail.com
\end{abstract}

Recebido em: 21/05/15

Aprovado em: 12/06/16 